Revista Brasileira de Agricultura Irrigada v.10, nº.4, p. 820 - 829, 2016

ISSN 1982-7679 (On-line)

Fortaleza, CE, INOVAGRI - http://www.inovagri.org.br

DOI: 10.7127/rbai.v10n400451

Protocolo 451.16 - 17/06/2016 Aprovado em 28/07/2016

\title{
LÂMINAS DE IRRIGAÇÃO E DOSES DE NITROGÊNIO EM ROSEIRAS CULTIVADAS COM TÉCNICAS DE PRODUÇÃO INTEGRADA
}

\author{
Eduardo Carvalho Oliveira ${ }^{1}$, Jacinto de Assunção Carvalho² ${ }^{2}$, Fátima Conceição Rezende ${ }^{3}$, \\ Elka Fabiana Aparecida Almeida ${ }^{4}$, Simone Novaes Reis ${ }^{5}$, Sônia Naomi Mimura ${ }^{6}$
}

\begin{abstract}
RESUMO
Poucas pesquisas envolvendo irrigação e adubação nitrogenada demonstram carência de informação sobre o nível ideal de aplicação de tais insumos na cultura da rosa. Além disso, a aplicação da quantidade ideal de água e nitrogênio está relacionada à utilização adequada de práticas agrícolas associadas à produção integrada, as quais se justificam com a economia desses insumos. Este trabalho objetivou avaliar o efeito de lâminas de irrigação e doses de nitrogênio sobre o rendimento e qualidade biométrica de hastes de rosas. O experimento foi realizado em casa de vegetação localizada em São João Del Rei - MG. Foi utilizado um delineamento em blocos casualizados com parcelas subdivididas, sendo as parcelas definidas por quatro níveis percentuais de lâminas de reposição de água no solo (40, 70, 100 e 130\%) e as subparcelas por quatro níveis percentuais de doses de nitrogênio (40, 70, 100 e 130\% da dose recomendada), com quatro repetições. Os parâmetros qualitativos avaliados das hastes florais foram influenciados com o incremento das lâminas de reposição. Maior produtividade foi obtida com reposição de $100 \%$ de água no solo e doses de nitrogênio iguais ou superiores a 100\%. O cultivo de rosas com técnicas de produção integrada é indicado.
\end{abstract}

Palavras-chave: Floricultura, Qualidade, Manejo da irrigação, Adubação

\section{WATER DEPTHS AND NITROGEN LEVELS IN ROSES CULTIVATED WITH TECHNIQUES OF INTEGRATED PRODUCTION}

\footnotetext{
${ }^{1}$ Eng. Agric. DS. em Recursos Hídricos em Sistemas Agrícolas, Universidade Federal de Lavras, Dep. de Engenharia, Campus Universitário, Caixa Postal 3037, CEP 37.200-000, Lavras, MG. e-mail: eduardoco@ig.com.br

${ }^{2}$ Eng. Agric. Prof. Dr. Universidade Federal de Lavras, Dep. de Engenharia, Campus Universitário, Caixa Postal 3037, CEP

37.200-000, Lavras, MG., e-mail: jacintoc@deg.ufla.br

${ }^{3}$ Eng. Agric. DS em Irrigação e Drenagem, Universidade Federal de Lavras, Dep. de Engenharia, Campus Universitário, Caixa Postal 3037, CEP 37.200-000, Lavras, MG., e-mail: frezende@deg.ufla.br

${ }^{4}$ Universidade Federal de Minas Gerais /ICA, Av. Universitária, no 1.000 bairro Universitário, Cep 39.404-547 - Montes Claros, MG, e-mail: elka@ufmg.br;

${ }^{5}$ Empresa de Pesquisa Agropecuária de Minas Gerais, Unidade Regional EPAMIG Sul de Minas, Av. Visconde do Rio Preto, s/n, Vila São Paulo, CEP: 36.301-360, São João Del Rei, MG; e-mail: sinore@bol.com.br

${ }^{6}$ Universidade Federal de São João Del Rei, e-mail: naomimurabio@gmail.com
} 


\begin{abstract}
Few studies involving amount of water irrigation and nitrogen demonstrates lack of information about the optimal application level of such inputs in the culture of the rose. Furthermore, the application of the optimum amount of water and nitrogen is related to the use of good agricultural practices, which are justified with the economy of these inputs. This work had the aim to evaluate the effect of irrigation and nitrogen on the yield and biometric quality of rose stems. The experiment was conducted in a greenhouse located at São João Del Rei, MG. Was used a randomized block design with split plots which the plots being defined by four percentage levels of water replacements on soil (40; 70; 100 and 130\%) and the subplots defined by four nitrogen fertilizer levels (40; 70; 100 and 130\%), with four replications. The quality parameters evaluated of the flowers are influenced by increasing water replacement. Higher yield is obtained with replacement of $100 \%$ soil moisture and nitrogen greater than or equal to $100 \%$. Cultivation of roses with techniques of integrated production is indicated.
\end{abstract}

Keywords: Floriculture, Quality, Irrigation management, Fertilization

\section{INTRODUÇÃO}

A floricultura brasileira vem adquirindo crescimento significativo e de acordo com Junqueira e Peetz (2008), está sendo considerado um dos segmentos mais promissores da horticultura intensiva e, dentre as flores de corte a rosa tem destaque especial devido sua grande utilização em muitas formas de ornamentações.

O cultivo da rosa de corte é uma atividade que exige capacitação do produtor e dos profissionais que atuam diretamente no setor. A adoção de técnicas tais como o cultivo em ambiente protegido, irrigação, fertirrigação, manejo adequado de pragas, doenças e plantas invasoras gerenciados de forma adequada, aumentam a produtividade, a qualidade das hastes florais bem como a receita líquida do produtor.

Buscando adequação para a sustentabilidade no cultivo da roseira, pode-se admitir que a aplicação da quantidade adequada de água e fertilizantes nitrogenados está relacionada às práticas agrícolas adequadas, podendo ser inserido às técnicas de produção integrada (PI), visando produzir flores com menores custos, boa rentabilidade e princípios sócioambientais.

O manejo da irrigação pode ser realizado com base em dados de clima ou no monitoramento do potencial de água do solo por meio de sensores de umidade. Para Blainski et al. (2009), o monitoramento com base no potencial de água no solo (tensão) é o mais difundido e de maior operacionalidade. Entretanto, no Brasil, o manejo da irrigação na floricultura tem se caracterizado pelo seu empirismo, muitas vezes com aplicação excessiva ou deficitária de água (ALVES et al, 2008). Todavia, irrigações em excesso aumentam os custos de produção, devido ao aumento no consumo de energia e lixiviação de nutrientes, além de poluir o meio ambiente e reduzir a produção (MAROUELLI et al., 2005). Chimonidou-Pavlidou (1999), relata que déficit hídrico severo é prejudicial ao desenvolvimento da roseira, reduzindo a produção em até $70 \%$, afetando a qualidade da flor e reduzindo o comprimento e o peso da haste floral. Por outro lado, a água em excesso também pode ser prejudicial para a roseira, pois reduz a aeração do substrato e causa o desenvolvimento anormal das plantas (KATSOULAS et al., 2006).

Alves et al. (2008) avaliando o efeito de diferentes níveis de irrigação (60, 80, 100, 120 e $140 \%$ da evaporação do tanque Classe A) na cultura da roseira, cultivada em ambiente protegido, verificaram que o número de hastes produzidas aumentou com o aumento dos níveis de irrigação adotados.

O nitrogênio é o nutriente mais exigido pelas roseiras (CFSEMG, 1999) e o suprimento adequado, estimula o crescimento da planta, favorecendo a emissão de novas folhas e brotos, 
maior área foliar e, consequentemente, maior fotossíntese. Huché-Thelier et al. (2011) avaliaram o efeito da aplicação de nitrogênio entre a fase inicial do botão floral até a fase em que a cor das pétalas é visível. Verificaram que a deficiência de nitrogênio apresentou efeitos, a longo prazo, na qualidade visual da planta e que as plantas submetidas a deficiência de nitrogênio apresentaram hastes mais assimétricas do que as plantas que não foram submetidas a deficiência do nutriente. Observaram também que a deficiência na fase de floração resultou em hastes maiores e mais vigorosas do que as plantas que não foram submetidas a deficiência de nitrogênio.

Assim, este trabalho objetivou avaliar o efeito de diferentes lâminas de irrigação e doses de nitrogênio sobre o rendimento e qualidade biométrica de hastes e botões de rosas, cultivadas em sistema de produção integrada.

\section{MATERIAL E MÉTODOS}

O experimento com a cultura da rosa (cv. Carola) foi conduzido em casa de vegetação, cujas dimensões são de 7,0 m de largura e 21,0 m de comprimento, totalizando 147,0 m². A área utilizada está localizada na Fazenda Experimental Risoleta Neves, da Empresa de Pesquisa Agropecuária de Minas Gerais (EPAMIG) em São João Del Rei/MG, a 889 metros de altitude e nas coordenadas geográficas

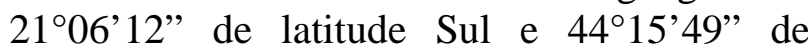
longitude Oeste de Greenwich. O clima da região é do grupo Cwa, de acordo com a classificação de Köppen, sendo temperado, caracterizado por verão úmido e inverno seco.

Um termohigrômetro digital foi instalado no interior da casa de vegetação e os dados da umidade relativa do ar e temperatura do ar (máximas, médias e mínimas) foram obtidos diariamente durante a condução do experimento.

O solo da área experimental foi classificado como Cambissolo Háplico Ta Eutroférrico. O potencial de água no solo, de 12 $\mathrm{kPa}$, equivalente à umidade na capacidade de campo foi obtida por meio de teste in loco. As análises físicas e de fertilidade foram realizadas no Laboratório de Física e Fertilidade do Solo do Departamento de Ciência do Solo da Universidade Federal de Lavras. As características físicas e químicas podem ser observadas na Tabela 1.

Tabela 1. Características físicas e químicas do solo da área do experimento.

\begin{tabular}{|c|c|c|c|c|c|c|c|c|c|c|}
\hline \multicolumn{11}{|c|}{ Análise física do solo ${ }^{(1)}$} \\
\hline Camada & Areia & Silte & Argila & Textura & $\rho_{g}$ & $\rho_{p}$ & $\theta_{\mathrm{cc}}$ & $\theta_{\mathrm{pm}}$ & $\theta_{\mathrm{r}}$ & $\theta_{\mathrm{s}}$ \\
\hline$(\mathrm{cm})$ & \multicolumn{3}{|c|}{$($ dag kg-1) } & & \multicolumn{2}{|c|}{$\left(\mathrm{g} \mathrm{cm}^{-3}\right)$} & \multicolumn{4}{|c|}{$\left(\mathrm{cm}^{3} \mathrm{~cm}^{-3}\right)$} \\
\hline $0-20$ & 38 & 21 & 41 & Argilosa & 1,28 & 2,74 & 0,384 & 0,264 & 0,260 & 0,617 \\
\hline $0-40$ & 39 & 20 & 41 & Argilosa & 1,28 & 2,74 & 0,371 & 0,250 & 0,245 & 0,581 \\
\hline \multicolumn{11}{|c|}{ Análise química do solo ${ }^{(2)}$} \\
\hline Camada & $\mathrm{MO}$ & & $\mathrm{pH}$ & $\mathrm{K}$ & $\mathrm{Ca}^{2+}$ & $\mathrm{Mg}^{2+}$ & $\mathrm{Al}^{3+}$ & $\mathrm{H}+\mathrm{Al}$ & $\mathrm{V}$ & $\mathrm{M}$ \\
\hline$(\mathrm{cm})$ & $\left(\right.$ dag kg $\left.^{-1}\right)$ & & $\left.\mathrm{H}_{2} \mathrm{O}\right)$ & $\left(\mathrm{mg} \mathrm{dm}^{-3}\right)$ & & $(\mathrm{cm}$ & $\left.l_{c} \mathrm{dm}^{-3}\right)$ & & & 6) \\
\hline $0-20$ & 1,3 & & 5,7 & 20 & 1,9 & 0,4 & 0,0 & 2,7 & 46,5 & 1,8 \\
\hline $20-40$ & 1,0 & & 5,9 & 16 & 1,9 & 0,4 & 0,0 & 2,2 & 51,6 & 2,0 \\
\hline Camada & P-rem & & SB & $(\mathrm{T})$ & Zn & $\mathrm{Fe}$ & $\mathrm{Mn}$ & $\mathrm{Cu}$ & B & $S$ \\
\hline$(\mathrm{cm})$ & $\left(\mathrm{mg} \mathrm{L}^{-1}\right)$ & \multicolumn{3}{|c|}{$\left(\mathrm{cmol}_{C} \mathrm{dm}^{-3}\right)$} & \multicolumn{6}{|c|}{$\left(\mathrm{mg} \mathrm{dm}^{-3}\right)$} \\
\hline $0-20$ & 7,7 & & 2,4 & 5,1 & 2,7 & 52,7 & 14,5 & 5,5 & 0,0 & 24,4 \\
\hline $20-40$ & 6,9 & & 2,3 & 4,5 & 0,7 & 51,3 & 10,4 & 4,4 & 0,1 & 28,9 \\
\hline
\end{tabular}

${ }^{(1)} \rho_{\mathrm{g}}$, densidade do solo; $\rho_{\mathrm{p}}$, densidade de partículas; $\theta_{\mathrm{cc}}$, umidade na capacidade de campo; $\theta_{\mathrm{pm}}$, umidade de ponto de murcha; $\theta_{\mathrm{r}}$, umidade residual; $\theta_{\mathrm{s}}$, umidade de saturação. ${ }^{(2)} \mathrm{MO}$, matéria orgânica; $\mathrm{pH}$, em água (1:2,5); P, fósforo disponível (Mehlich 1); K, potássio disponível; $\mathrm{Ca}^{2+}$, cálcio trocável; $\mathrm{Mg}^{2+}$, magnésio trocável; $\mathrm{Al}^{3+}$, acidez trocável; $\mathrm{H}+\mathrm{Al}$, acidez potencial; $\mathrm{V}$, saturação por bases; m, saturação por alumínio; P-rem, fósforo remanescente; SB, soma de bases; (t), CTC efetiva; (T), CTC a pH 7,0; Zn, zinco disponível; Fe, ferro disponível; Mn, manganês disponível; Cu, cobre disponível; B, boro disponível; S, enxofre disponível. 
A curva característica de retenção da água do solo foi obtida experimentalmente; os valores ajustados estão representados pelas Equações 1 $\left(\mathrm{R}^{2}=0,983\right)$ e $2\left(\mathrm{R}^{2}=0,976\right)$ para as camadas de solo de 0 a 0,20 e 0 a $0,40 \mathrm{~cm}$, respectivamente.

$$
\begin{aligned}
& \theta=0,260+\frac{0,357}{\left[1+(0,3597 \cdot|\psi|)^{1,7000}\right]^{0,4118}} \\
& \theta=0,245+\frac{0,336}{\left[1+(0,3273 \cdot|\psi|)^{1,6866}\right]^{0,4071}}
\end{aligned}
$$

em que: $\theta=$ umidade com base em volume $\left(\mathrm{cm}^{3}\right.$ $\left.\mathrm{cm}^{-3}\right)$ e $\Psi=$ potencial de água no solo $(\mathrm{kPa})$.

Utilizou-se um delineamento em blocos casualizados (DBC) com parcelas subdivididas, sendo as parcelas definidas por quatro níveis percentuais de lâminas (W) de reposição de água no solo (40; 70; 100 e 130\%) e as subparcelas definidas por quatro doses de adubação nitrogenada (N) no solo (40; 70; 100 e 130\% da dose recomendada), com quatro repetições.

As mudas da rosa cv. Carola foram obtidas por enxertia e transplantadas no dia 03/02/2011 em canteiros de $0,2 \mathrm{~m}$ de altura, com espaçamento de $0,20 \mathrm{~m}$ entre plantas e $1,2 \mathrm{~m}$ entre linhas. Os canteiros formavam as unidades experimentais, cada uma contendo cinco plantas.

Na adubação de plantio foram utilizados o termofosfato magnesiano, nitrato de potássio e sulfato de amônio conforme recomendação da CFSEMG (1999), adaptadas para 40.000 plantas. A adubação de cobertura foi realizada via fertirrigação e as fontes de adubo utilizados foram o fosfato monopotássico, sulfato de potássio, sulfato de magnésio, nitrato de cálcio e uréia. Na adubação de cobertura o nitrogênio foi aplicado conforme definido nos tratamentos (40; $70 ; 100$ e $130 \%$ de $N$ ) e quantidade do nutriente foi dividida em aplicações quinzenais. Os micronutrientes eram aplicados via fertirrigação e pulverização foliar usando um coquetel contendo todos os microelementos.

Durante 45 dias (do plantio até 20/03/2011), adotado como um período de pegamento das plantas, todos os tratamentos foram irrigados quando o potencial da água no solo atingia um valor de $15 \mathrm{kPa}$ aplicando a lâmina de água necessária para elevar o solo à capacidade de campo. Neste período as adubações de cobertura foram realizadas, mensalmente conforme recomendação de CFSEMG (1999), aplicando-se 100\% dos nutrientes, sem alteração nas doses de nitrogênio.

O sistema de irrigação utilizado foi o gotejamento, com gotejadores autocompensantes, operando com pressão de serviço na faixa de 5 a 35 m.c.a., do tipo in-line (tubo gotejador), distanciados entre si de $0,20 \mathrm{~m}$ e vazão nominal de $1,6 \mathrm{~L} \mathrm{~h}^{-1}$, configurando um gotejador por planta. Cada repetição das unidades experimentais foram instaladas duas linhas laterais de tubo próximo às plantas. Uma das linhas laterais foi utilizada para reposição de água no solo (W), enquanto a outra aplicava nutrientes via fertirrigação de acordo com a variação dos tratamentos (doses de $\mathrm{N}$ ).

O funcionamento do sistema de irrigação e fertirrigação foi automatizado utilizando válvulas de comando elétrico localizadas na saída do cabeçal de controle. Nas parcelas do tratamento com reposição de $100 \%$ de água no solo foram instalados tensiômetros nas profundidades de 0,20 e $0,40 \mathrm{~m}$ para monitoramento do potencial de água no solo. Os tensiômetros foram instalados entre as plantas no alinhamento da cultura. A leituras foram feitas com um tensímetro de punção, digital, duas vezes ao dia, as $9 \mathrm{~h} 00$ e as $15 \mathrm{~h} 00$. Os tratamentos foram irrigados quando a média da leitura de três tensiômetros acusavam um potencial de $-20 \mathrm{kPa}$ e as lâminas foram aplicadas com base nos percentuais definidos para cada tratamento.

A aplicação dos nutrientes via água de irrigação era realizada com base no tempo definido para aplicação de água no tratamento de 40\%. Nos demais tratamentos (70, 100 e 130\%) o tempo de aplicação de nutrientes era descontado do tempo total de aplicação, não interferindo na lâmina total necessária.

Até os 90 dias após o transplantio (DAT), a irrigação foi realizada com base nas leituras dos tensiômetros instalados a $0,20 \mathrm{~m}$ de profundidade. Após este período, adotou-se a 
leitura dos tensiômetros instalados a 0,40 m de profundidade.

Realizou-se um manejo integrado de pragas, doenças e plantas daninhas com pulverizações preventivas semanalmente com defensivos alternativos (Beauveria bassiana, Metharhizium anisopliae, óleo de Nim, bicarbonato de sódio e leite crú), as plantas daninhas foram retiradas por meio de capina manual; a sanitização foi mantida através da eliminação contínua de folhas, ramos e flores doentes.

Durante o desenvolvimento do experimento foram realizados os seguintes tratos culturais: desponta (retirada das primeiras folhas da muda para quebrar a dominância apical); agóbio (rebaixamento lateral da planta sem a danificação do caule, visando à formação de uma massa foliar capaz de gerar hastes de qualidade) e desbrotas (retirada dos brotos secundários, evitando a deformação da haste).

As colheitas se iniciaram quando pelo menos $50 \%$ das hastes apresentaram-se em ponto de corte, compreendendo o período entre 31/05/2011 a 30/05/2012, totalizando 12 meses. $\mathrm{O}$ ponto de colheita era determinado quando as sépalas da inflorescência se mostravam totalmente abertas e as pétalas em início de abertura. O corte de cada haste era realizado na segunda folha de cinco folíolos contados a partir do ponto em que a haste brotou.

A produtividade de rosas foi contabilizada por todas as hastes colhidas nas cinco plantas de cada parcela experimental, considerando hastes comerciais àquelas que se apresentavam retas, sem o botão floral torto ou com quaisquer defeitos de formação e com comprimento mínimo de 40, 50 e $60 \mathrm{~cm}$, segundo classificação do IBRAFLOR (2000). As hastes que, visualmente, se apresentavam fora dos padrões de classificação (defeitos de formação ou ataques por pragas e/ou doenças) não eram colhidas, utilizando-se nestas, a técnica do agóbio. As hastes florais colhidas eram acondicionadas em feixes e etiquetadas com a denominação de cada unidade experimental e planta.
Foram avaliados a produtividade comercial de hastes florais (planta ${ }^{-1} \mathrm{ano}^{-1}$ ), $\mathrm{o}$ comprimento e diâmetro das hastes e o comprimento e diâmetro do botão floral. Os dados coletados foram analisados estatisticamente através de análise de variância, com realização do teste $\mathrm{F}(1 \%$ e $5 \%$ de probabilidade) e por meio de regressão com o auxílio do software SISVAR (FERREIRA, 2011).

\section{RESULTADOS E DISCUSSÃO}

Durante o período de condução do experimento a temperatura média do ar no interior da casa de vegetação foi de $25,3^{\circ} \mathrm{C}$; as médias das mínimas e máximas observadas foram de 15,4 e $35,2^{\circ} \mathrm{C}$, respectivamente. A umidade relativa média observada ao longo do experimento foi de $56,4 \%$, com máxima média de $77,1 \%$ e mínima média de $35,7 \%$. De acordo com Nau (2011), a temperatura ótima para desenvolvimento da maioria das cultivares de rosa varia de $18^{\circ} \mathrm{C}$ à $24^{\circ} \mathrm{C}$, admitindo-se uma temperatura mínima de $16^{\circ} \mathrm{C}$ durante a noite e máxima de $30^{\circ} \mathrm{C}$ durante o dia e que requerem uma umidade ambiental relativamente elevada.

No período de estabelecimento da cultura, que perdurou por 45 dias após o transplantio das mudas, aplicou-se uma lâmina total de 128,63 mm e 53,33 $\mathrm{kg} \mathrm{ha}^{-1}$ de nitrogênio. Após este período, as lâminas de irrigação e as doses de nitrogênio foram calculadas e aplicadas separadamente, conforme os tratamentos.

Na Tabela 2 podem ser verificadas as lâminas totais, o número de irrigações realizadas durante o período (12 meses), a lâmina média por irrigação, a quantidade total de nitrogênio aplicada durante o mesmo período, o número de adubações considerando aplicações quinzenais e a quantidade média de nitrogênio, em função dos tratamentos de reposição de água no solo e doses de nitrogênio.

A Tabela 3 apresenta o resumo da análise de variância para todos os parâmetros estudados. As lâminas de irrigação (W) influenciaram significativamente no comprimento da 
Tabela 2. Lâmina total aplicada, número de irrigações, lâmina média por irrigação, nitrogênio total aplicado, número de aplicações de nitrogênio e dose média de nitrogênio por aplicação,

\begin{tabular}{cccc}
\hline Lâmina (\%) & Lâmina total $(\mathrm{mm})$ & $\begin{array}{c}\text { Número total de } \\
\text { irrigações }\end{array}$ & $\begin{array}{c}\text { Lâmina média por } \\
\text { irrigação }(\mathrm{mm})\end{array}$ \\
\hline 40 & 785,33 & 124 & 6,33 \\
70 & 1374,33 & 124 & 11,08 \\
100 & 1963,33 & 124 & 15,83 \\
130 & 2552,32 & 124 & 20,58 \\
\hline \multirow{2}{*}{ Nitrogênio (\%) } & Nitrogênio total & Número total de & Dose média por \\
& $\left(\mathrm{kg} \mathrm{ha}^{-1}\right.$ ano $\left.^{-1}\right)$ & aplicações & aplicação $\left(\mathrm{kg} \mathrm{ha}^{-1}\right)$ \\
\hline 40 & 192,00 & 24 & 8,00 \\
70 & 336,00 & 24 & 14,00 \\
100 & 480,00 & 24 & 20,00 \\
130 & 624,00 & 24 & 26,00 \\
\hline
\end{tabular}

haste, no comprimento e diâmetro médio do botão floral e no número de hastes por planta. Não houve diferença estatística significativa em relação às doses de nitrogênio $(\mathrm{N})$ para nenhum dos parâmetros avaliados. A interação entre lâminas de irrigação e nitrogênio (W x N) influenciou significativamente somente o número de hastes por planta. A influência da irrigação sobre a produtividade da roseira cultivada em ambiente protegido foi observada por Katsoulas et al. (2006), Alves et al. (2008) e Cavalcanti Júnior et al. (2013).

Tabela 3. Resumo da análise de variância para as médias do comprimento (CH) e diâmetro (DH) da haste, comprimento (CB) e diâmetro do botão (DB) floral e número de hastes por planta (HP) da roseira (produtividade), em função das lâminas de irrigação (W) e doses de nitrogênio (N).

\begin{tabular}{lcccccc}
\hline Fonte de & Grau de & \multicolumn{5}{c}{ Quadrado Médio } \\
\cline { 3 - 7 } Variação & Liberdade & CH (cm) & DH (mm) & CB $(\mathrm{mm})$ & DB $(\mathrm{mm})$ & HP \\
\hline Lâmina (W) & 3 & $192,94^{*}$ & $0,21^{\mathrm{NS}}$ & $7,17^{* *}$ & $5,81^{* *}$ & $107,49^{* *}$ \\
Bloco & 3 & $139,94^{\mathrm{NS}}$ & $0,19^{\mathrm{NS}}$ & $0,65^{\mathrm{NS}}$ & $2,23^{\mathrm{NS}}$ & $5,39^{\mathrm{NS}}$ \\
Resíduo 1 & 9 & 32,03 & $0,15^{\mathrm{NS}}$ & 0,39 & 0,76 & 1,31 \\
Nitrog. (N) & 3 & $33,84^{\mathrm{NS}}$ & $0,12^{\mathrm{NS}}$ & $0,46^{\mathrm{NS}}$ & $1,36^{\mathrm{NS}}$ & $5,09^{\mathrm{NS}}$ \\
W x N & 9 & $37,00^{\mathrm{NS}}$ & $0,09^{\mathrm{NS}}$ & $0,96^{\mathrm{NS}}$ & $0,72^{\mathrm{NS}}$ & $5,87^{* *}$ \\
Resíduo 2 & 36 & 34,19 & 0,11 & 0,46 & 0,63 & 1,96 \\
\hline Média geral & & 92,46 & 7,87 & 53,16 & 36,43 & 14,72 \\
\hline Coef. de variação 1 (\%) & 6,12 & 4,99 & 1,18 & 2,40 & 7,79 \\
Coef. de variação 2 (\%) & 6,32 & 4,29 & 1,28 & 2,18 & 9,51 \\
\hline
\end{tabular}

*: Significativo, a 5\% de probabilidade; **: Significativo, a $1 \%$ de probabilidade; ${ }^{\text {NS }}$ Não significativo.

A Figura 1, apresenta o comprimento da haste (A), comprimento do botão floral (B), diâmetro do botão floral (C) e o número de hastes por planta (D) em função das lâminas de irrigação. Verificase que as maiores médias dessas características foram obtidas com irrigações próximas ou superiores a $100 \%$ de reposição, indicando que a roseira é exigente em relação à água para realizar seus processos fisiológicos para produzir hastes florais de qualidade comercial.
O comprimento da haste é a principal característica observada na classificação da haste floral da roseira, sendo aquelas com comprimento entre 60 e $90 \mathrm{~cm}$ as mais valorizadas. A Figura $1 \mathrm{~A}$ apresenta $\mathrm{o}$ comprimento da haste em função dos tratamentos de irrigação e derivando a equação de regressão o melhor resultado é obtido com $124,2 \%$ de reposição de água no solo e hastes com 95,49 cm. A média geral para o comprimento da haste floral foi de 92,46 cm (Tabela 3), sendo este valor superior àqueles 
encontrados por Barguil et al. (2010) e Villas Bôas et al. (2008) para a roseira cv. Carola.

O comprimento médio do botão floral apresentou tendência de crescimento na forma polinomial quadrática (Figura 1B) e variou entre 52,34 e 53,76 mm da menor (40\%) para a maior lâmina de reposição de água no solo (130\%). Derivando a equação polinomial o maior valor de comprimento do botão floral $(54,62 \mathrm{~cm})$ foi
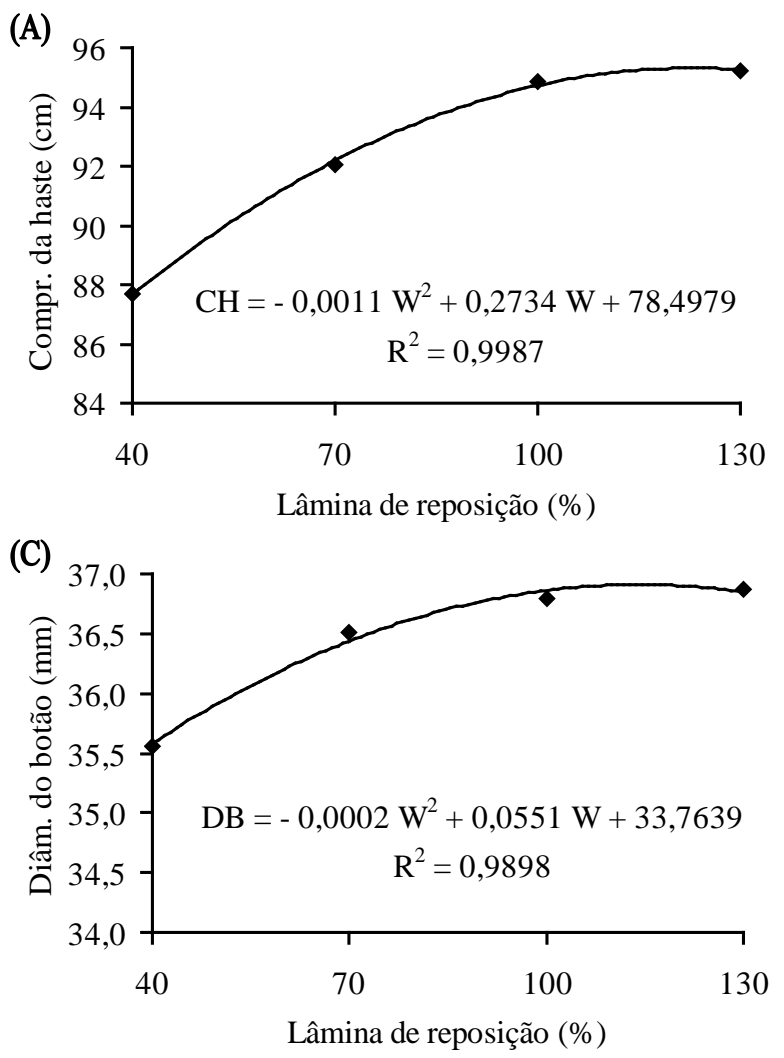

obtido com 191,07\% de reposição de água no solo. Este resultado permite classificar os botões na categoria de grande, pois de acordo com o IBRAFLOR (2000), comprimento do botão floral acima de $50 \mathrm{~mm}$ são considerados de tamanho grande. Valores médios do comprimento do botão floral, iguais a 51,60 mm, foram observados por Barguil et al. (2010), para a cv. Carola.
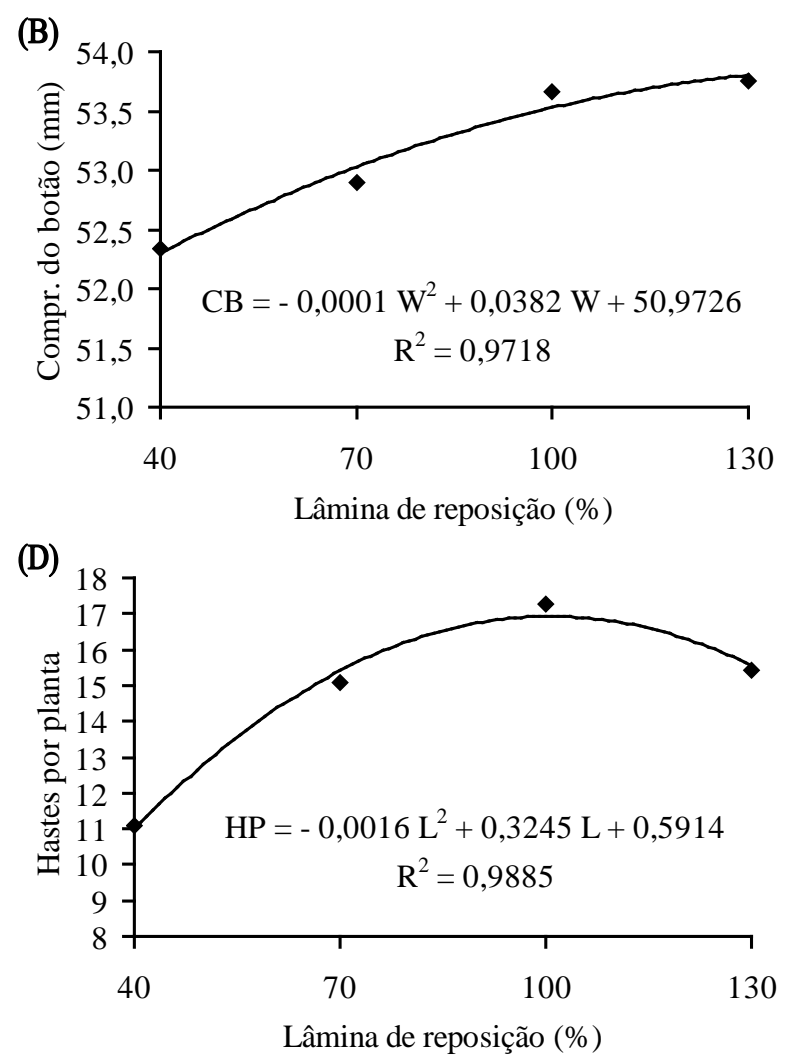

Figura 1. Comprimento da haste (A), comprimento (B) e diâmetro do botão floral (C) e número de hastes por planta (D), em função das lâminas de reposição de água no solo (W).

Conforme verificado na Figura 1C, o diâmetro do botão floral aumentou de acordo com o incremento de reposição de água no solo, obtendo bom ajuste na forma polinomial quadrática $\left(\mathrm{R}^{2}=98,98 \%\right)$. O valor ótimo de diâmetro do botão floral $(37,56 \mathrm{~cm})$ é obtido com uma lâmina de reposição de água no solo de $137,75 \%$. O diâmetro médio do botão floral observado foi igual a $36,43 \mathrm{~mm}$, sendo o mesmo superior àquele observado por Villas Bôas et al. (2008), em que o diâmetro do botão floral da rosa cv. Carola cultivada em ambiente protegido foi de $28,7 \mathrm{~mm}$. Diâmetro médio de botão floral de 34,0 $( \pm 0,5) \mathrm{mm}$ foi obtido por Marinho et al. (2013), em trabalho com roseira híbrida
Ambiance, cultivada em ambiente protegido. e submetidas a diferentes de lâminas de irrigação.

Os efeitos do estresse hídrico em diferentes estágios de desenvolvimento da cultura da roseira foram avaliados por Chimonidou-Pavlidou (2004). Segundo o autor, o desenvolvimento do botão floral é muito sensível ao estresse hídrico antes da formação das pétalas e dos estames. Nesses estágios o estresse de água afetou a qualidade das flores, reduzindo o número de pétalas bem formadas e o comprimento do botão floral.

Na Figura 1D observa-se que a produtividade de hastes comerciais por planta, reduziu com a aplicação de lâmina inferior e 
superior a 100\% de reposição de água no solo. Maior número de hastes comerciais foi obtido com a aplicação de lâmina correspondente a $101,41 \%$ de reposição de água, com produção de $35,7 \%$ superior ao que foi obtida no tratamento com reposição de água de $40 \%$, sendo esta a pior produtividade verificada. Do mesmo modo, as diferenças na produtividade de hastes comerciais foram 12,5 e $10,5 \%$ menores para os tratamentos de 70 e $130 \%$ de reposição, respectivamente. Nota-se, ainda, pela Figura 1D, que não houve variação expressiva na produção de hastes entre as lâminas de $70 \%$ a $130 \%$ de reposição de água, porém, de maneira geral, o déficit e o excesso hídrico afetaram a quantidade de hastes produzidas por planta da roseira.

Com base nos dados obtidos verifica-se que a água é essencial para o rendimento da cultura da roseira e que ela responde positivamente às irrigações quando estas mantêm o solo em sua umidade na capacidade de campo. Resultados semelhantes foram notados por Alves et al. (2008) e Bolla et al. (2010) para a roseira; Bastug et al. (2006) e Pereira et al. (2009) trabalhando com irrigações sobre a cultura do gladíolo e Rego et al. (2009) com a cultura do crisântemo irrigado.

Casarini et al. (2007), trabalhando com doses de nitrogênio e potássio iguais a 10, 20, 30 e 40 g planta $^{-1}$ ano $^{-1}$ sobre a cultura da roseira cv. Versilia, não observaram diferenças significativas na produtividade entre as doses de nitrogênio aplicadas. O mesmo foi observado por Cabrera (2000), que avaliou a produtividade de rosas em ambiente protegido sob diferentes doses de nitrogênio, não observando diferença entre os tratamentos em colheitas realizadas durante o inverno, obtendo resultado oposto de produtividade e matéria seca durante o verão. De acordo com Huché-Thélier et al. (2011), a deficiência de nitrogênio durante o desenvolvimento de ramos primários modifica significativamente algumas características visuais da planta, ou seja reduz a produção de botões florais na região apical e aumenta a produção nas regiões basal e média.

Pela superfície de resposta apresentada na Figura 2, verifica-se a produtividade em função da interação entre os tratamentos de lâminas de reposição de água e doses de nitrogênio ( $\mathrm{W}$ x N). Os valores de produtividade foram ajustados por meio de uma equação na forma polinomial quadrática (Equação 3), obtendo $\mathrm{R}^{2}$ igual a $90,61 \%$.

$$
\mathrm{HP}=1,5871+0,2821 \cdot \mathrm{W}+0,0128 \cdot \mathrm{N}-0,0016 \cdot \mathrm{W}^{2}-0,0002 \cdot \mathrm{N}^{2}+0,0005 \cdot \mathrm{W} \cdot \mathrm{N}
$$

em que HP é a produtividade (número de hastes planta $\left.^{-1}\right)$; $\mathrm{W}$ é a lâminas de reposição de água (\%) e $\mathrm{N}$ é a doses de nitrogênio (\%).

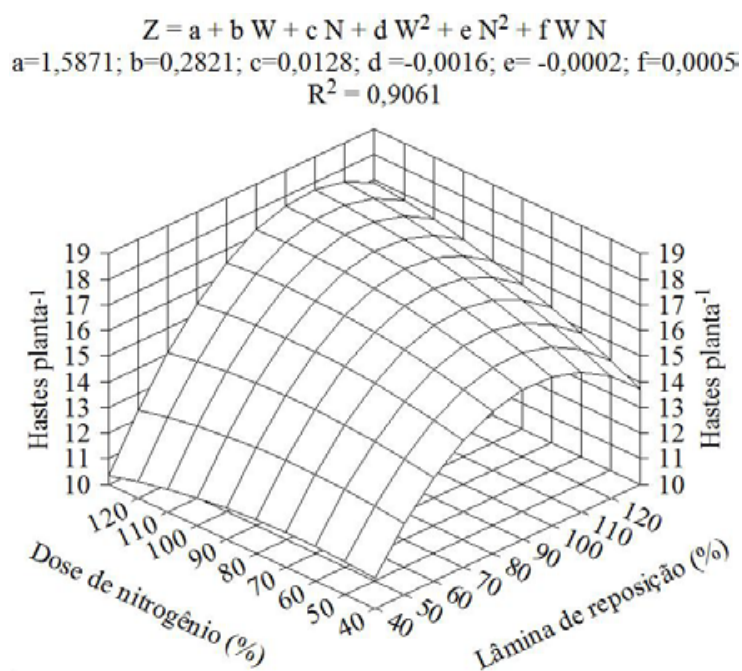

Figura 2. Produtividade em função da interação entre os tratamentos de lâminas de irrigação e doses de nitrogênio $(\mathrm{W} x \mathrm{~N})$. 
As maiores médias de produtividade foram obtidas pela combinação de lâminas de reposição de água próximas a 100\% e com aplicação de doses de nitrogênio variando de $97 \%$ a 130\%. Considerando uma lâmina de $100 \%$ de reposição de água no solo e dose de nitrogênio de $97 \%$ a produtividade ótima seria de 18 hastes por planta. Aplicações excessivas de nitrogênio ao solo podem acarretar em salinização, prejudicando a absorção de nutrientes pelas plantas e alterando seu metabolismo. Em condições salinas, ocorre uma redução na disponibilidade de água, ou seja, com o acúmulo de sais no solo o potencial total da água do solo tende a uma redução, ocasionado pela contribuição do potencial osmótico.

Segundo Casarini et al. (2007), a quantidade de fertilizantes a aplicar para qualquer cultura deve ser a mais próxima possível do que é extraído pela mesma, pois existe o risco de salinização do solo devido ao acúmulo de sais na região do sistema radicular. Villas Bôas et al. (2008) relatam que o nitrogênio é absorvido em maior quantidade na fase de crescimento vegetativo quando a planta desenvolve mais massa foliar e reservas de carboidratos que posteriormente serão usados na formação dos ramos basais.

De forma geral, a produtividade de acordo com os resultados deste experimento apontou valor máximo de 72 hastes $\mathrm{m}^{-2}$ ano $^{-1}$ para a lâmina de reposição de $100 \%$; no entanto, esse resultado foi obtido com um espaçamento adotado de $0,2 \times 1,2 \mathrm{~m}$, considerando 40.000 plantas ha ${ }^{-1}$ e que não houve interferência bulbos molhados no solo e das doses de nitrogênio entre as parcelas experimentais

\section{CONCLUSÕES}

1. Os principais parâmetros qualitativos das hastes florais da roseira são influenciados positivamente com o aumento das lâminas de reposição de água no solo;

2. A produtividade da roseira é afetada pelo déficit e excesso hídrico de maneira geral, obtendo maiores valores com a reposição de $100 \%$ de água no solo;
3. A maior produtividade foi obtida com dose de $\mathrm{N}$ variando de $97 \%$ a $130 \%$;

4. O cultivo de rosas sob técnicas de produção integrada é indicado, uma vez que acarreta em boas produtividades e hastes florais de qualidade;

\section{AGRADECIMENTOS}

Os autores agradecem à Fundação de Amparo à Pesquisa do Estado de Minas Gerais - FAPEMIG pelo apoio financeiro ao projeto.

\section{REFERÊNCIAS}

ALVES, A. M.; VIANA. T. V. de A.; AZEVEDO, B. M. de; JOVINO, M. R. M.; FURLAN. R. A. Efeitos de níveis de irrigação sobre a cultura da rosa. Irriga, v.13, n.2, p.152159, 2008

BARGUIL, B. M.; VIANA, F. M. P.; MOSCA, J. L. Características morfológicas e fitossanitárias de variedades de roseira na etapa de classificação. Ciência Rural, v.40, n.7, 2010.

BASTUG, R.; KARAGUZEL, O.; AYDINSAKIR, K.; BUYUKTAS, D. The effects of drip irrigation on flowering and flower quality of glasshouse gladiolus plant. Agricultural Water Management, v.81, n.1-2, p.132-144, 2006.

BLAINSKI, E.; GONÇALVES, A. C. A.; TORMENA, C. A.; FOLEGATTI, M. V.; GUIMARÃES, R. M. L. Intervalo hídrico ótimo num nitossolo vermelho distroférrico irrigado. Revista Brasileira de Ciência do Solo,Viçosa, v.33, n.2, p.273-281, 2009.

BOLLA, A.; VOYIATZIZ, D.; KOUKOURIKOU-PETRIDOU, $\quad$ M.; CHIMONIDOU, D. Photosynthetic parameters and cut-flower yield of rose "Eurored" (HT) are adversely affected by mild water stress irrespective of substrate composition. Scientia Horticulturae, v. 126, n.3, p.390-394, 2010 
CABRERA, R. I. Evaluating yield and quality of roses with respect to nitrogen fertilization and leaf nitrogen status. Acta Horticulturae, n. 511, p.133- 141, 2000

CASARINI, E.; FOLEGATTI, M. V.; SILVA, E. F. F. Produtividade da roseira em função de doses de nitrogênio e potássio aplicadas via fertirrigação em ambiente protegido. Magistra, v.19, n.3, p.250-256, 2007.

CAVALCANTE JÚNIOR, J. A.; AZEVEDO, B. M. de; SOUSA, G .G. de; VASCONCELOS, D. V.; VIANA, T. V. de A.; REBOUÇAS NETO, M. de O. Manejo da irrigação na cultura da roseira em ambiente protegido. Revista Brasileira de Agricultura Irrigada, v. 7, n. 4, p. 269-276, 2013

CFSEMG - COMISSÃO DE FERTILIDADE DO SOLO DO ESTADO DE MINAS GERAIS. Recomendações para o uso de corretivos e fertilizantes em Minas Gerais: $5^{\text {a }}$ aproximação. Viçosa, MG: UFV, 1999.

CHIMONIDOU-PAVLIDOU, D. Irrigation and sensitive stages of rose development. Acta Horticulturae, n.481, p.393-401, 1999.

CHIMONIDOU-PAVLIDOU, D. Malformation of roses due to drought stress. Scientia Horticulturae, v.99, n.1-2, p. 79-87, 2004.

FERREIRA, D.F. Sisvar: a computer statistical analysis system. Ciência e Agrotecnologia, , v.35, n.6, p.1039-1042, 2011.

HUCHÉ-THÉLIER， L.; BOUMAZA， R.; DEMOTES-MAINARD, S.; CANET, A.; SIMONEAUX, R.; DOUILLET, O.; GUÉRIN, $\mathrm{V}$. Nitrogen deficiency increase basal branching and modifies visual quality of the rose bushes. Scientia Horticulturae, v. 130, n.1, p.325-334, 2011

IBRAFLOR - Instituto Brasileiro de Floricultura. Padrão Ibraflor de qualidade. São Paulo: IBRAFLOR, 2000. 87p.
JUNQUEIRA, H. E.; PEETZ, M. da S. Mercado interno para os produtos da floricultura brasileira: características, tendências e importância socioeconômica recente. Revista Brasileira de Horticultura Ornamental, v. 14, n.1, p. 37-52, 2008

KATSOULAS, N.; KITTAS, C.; DIMOKAS, G.; LIKAS, C. Effect of irrigation frequency on rose flower production and quality. Biosystems Engineering, v.93, n.2, p.237-244, 2006.

MARINHO, L. E.; TONETTI, A. L.; STEFANUTTI, R.; CORAUCCI-FILHO, B. Application of reclaimed wastewater in the irrigation of rosebushes. Water. Air \& Soil Pollution, v. 224, n. 9, artigo 1669, 2013

MAROUELLI, W. A.; CALBO, A. G.; CARRIJO, O. A. Avaliação de sensores do tipo irrigas para o controle da irrigação em hortaliças cultivadas em substratos. Irriga, v.10, n.1, p.8895, 2005.

NAU, J. Ball redbook.18th ed. Crop production. United States of America: Ball, 2011. v. 2, 832 p.

PEREIRA, J. R. D.; CARVALHO, J. de A.; PAIVA, P. D. de O.; SILVA, D. J. da; SOUZA, A. M. G. de; SOUZA, K; J. de. Crescimento e produtividade de hastes florais de gladíolo cultivado sob diferentes tensões de água no solo. Ciência e Agrotecnologia, v.33, n.4, p.965-970, 2009.

REGO, J. L.; VIANA, T. V. de A.; AZEVEDO, B. M. de; ARAÚJO, W. F.; FURLAN, R. A.; BASTOS, F. G. C. Produtividade de crisântemo em função de níveis de irrigação. Horticultura Brasileira, v.27, n.1, p.045-048, 2009.

VILLAS BÔAS, R. L.; GODOY, L. J. G. de; BACKES, C.; LIMA, C. P. de; FERNANDES, D. M. Exportação de nutrientes e qualidade de cultivares de rosas em campo e em ambiente protegido. Horticultura Brasileira, v.26, n.4, p.515-519, 2008. 